\title{
PADRONIZAÇÃO DO TESTE DE ECLODIBILIDADE DE OVOS: DIAGNÓSTICO IN VITRO DA RESISTÊNCIA AO ALBENDAZOL EM NEMATOIDES GASTRINTESTINAIS
}

\author{
Marcela Santos Sena Martins \\ Isabella Vilhena Freire Martins ${ }^{* *}$
}

\begin{abstract}
RESUM0: 0 objetivo deste trabalho foi padronizar, adaptar e detalhar o teste de eclodibilidade de ovos (TEO) para 0 diagnóstico da resistência de nematoides gastrintestinais de ovinos ao albendazol. Para a realização do teste in vitro foram realizados três ensaios em dois momentos (24 e 48h), executados segundo metodologia preconizada pelo Manual Prático da EMBRAPA, utilizando controle negativo com água destilada e DMSO a 0,75\% e tratamento com concentrações de 600, 300, 150, 112,5, 75, 37,5, 18,75, 9,37 e 4,68 $\mu \mathrm{g} / \mathrm{mL}$ e controle positivo albendazol $25.000 \mu \mathrm{g} / \mathrm{mL}$. Seguiu-se incubação das placas em estufa com demanda bioquímica de oxigênio (DB0), mantidos à temperatura de $28^{\circ} \mathrm{C}$. Após $24 \mathrm{~h}$ e $48 \mathrm{~h}$ de incubação foi possível observar larvas eclodidas nos grupos controle negativo e também nos grupos tratados com a concentração de $112,5 \mu \mathrm{g} / \mathrm{mL}$ e $75 \mu \mathrm{g} /$ $\mathrm{mL}$, respectivamente. Neste estudo não foi possível diagnosticar a resistência anti-helmíntica no TE0, devido a variáveis limitantes, como ausência de dose discriminante para 0 albendazol, porém foi possível a padronização, a adaptação e 0 detalhamento do mesmo para diagnóstico da resistência anti-helmíntica dos nematoides ao albendazol.
\end{abstract}

PALAVRAS-CHAVE: Benzimidazol; Helmintos; Ruminantes.

\section{STANDARDIZATION OF EGG HATCH ASSAY (EHA): IN VITRO DIAGNOSIS OF RESISTANCE TO ALBENDAZOLE IN GASTROINTESTINAL NEMATODES}

\begin{abstract}
Current analysis standardized, adapted and detailed Egg Hatch Assay (EHA) to diagnose the resistance of gastrointestinal nematodes to albendazole in sheep. Three in vitro assays were undertaken at 24 and $48 \mathrm{~h}$, by methodology prescribed by the EMBRAPA Practical Handbook, with negative control distilled water and DMSO at $0.75 \%$ and concentration at $600,300,150,112.5,75,37.5,18.75,9.37$ and $4.68 \mu \mathrm{g} / \mathrm{mL}$ and positive control albendazole $25.000 \mu \mathrm{g} / \mathrm{mL}$. Plates were incubated in buffer with BOD and maintained at $28^{\circ} \mathrm{C}$. After $24 \mathrm{~h}$ and $48 \mathrm{~h}$ of incubation, larvae had eclosion in negative control groups and also in groups treated with $112.5 \mu \mathrm{g} / \mathrm{mL}$ and $75 \mu \mathrm{g} / \mathrm{mL}$, respectively. It was not possible to diagnose anti-helminth resistance in EET due to limiting variables, such as the lack of discriminating dose for albendazole. The standardization, adaptation and detailing were possible to diagnose anti-helminth resistance of nematodes to albendazole.
\end{abstract}

KEYWORDS: Benzimidazol; Helminths; Ruminants.

\section{INTRODUÇÃO}

0 uso intensivo dos anti-helmínticos levou a um impacto positivo inicial durante um período pequeno, mas atualmente constitui a forma mais adversa de controle, se utilizada de maneira isolada (FORTES; MOLENTO, 2013), pois resulta na seleção e propagação de parasitos resistentes, favorecendo o aparecimento da resistência anti-helmíntica em vários países (KAPLAN; VIDYASHANKAR, 2012), incluindo o Brasil (AMARANTE et al., 2004).

Segundo Fortes e Molento (2013), a seleção e o crescimento de populações resistentes aos principais

\footnotetext{
* Médica Veterinária pela Universidade Federal do Espírito Santo (UFES). Mestre em Ciências Veterinárias pela Universidade Federal de Mato Grosso do Sul (UFMS), Mato Grosso do Sul, Brasil. E-mail: marcelasena2@hotmail.com

${ }^{* *}$ Docente Associada do Departamento de Medicina Veterinária do Centro de Ciências Agrárias e Engenharias da Universidade Federal do Espírito Santo (UFES), Espírito Santo, Brasil.
} 
grupos de anti-helmínticos, avermectinas, imidotiazois e benzimidazóis (BZs), constituem um sério obstáculo à criação de ruminantes no mundo todo. Sendo assim, métodos sensíveis e eficazes na detecção e monitoramento de populações resistentes se tornam imprescindíveis, principalmente na tomada de decisão relacionada ao controle parasitário nesses animais.

Nos estudos de campo, os testes utilizados e preconizados pela World Association for the Advancement of Veterinary Parasitology (WOOD et al., 1995) envolvem eutanásia de animais e, portanto, nas condições atuais, 0 teste de redução na contagem de ovos nas fezes (TRCOF) é a principal ferramenta usada no campo para o diagnóstico da resistência. 0 teste é de execução simples e pode ser realizado com todos os grupamentos de anti-helmínticos, independentemente de seu mecanismo de ação. Porém, vem recebendo críticas e sofrido alterações ao longo do tempo, sendo necessária a padronização e implementação de testes in vitro para melhorar a sensibilidade do diagnóstico da resistência, porém, sua disponibilidade é muito limitada, com poucos laboratórios no Brasil habilitados a realizá-los.

0 teste mais comum utilizado para avaliar a eficácia dos BZs in vitro é o de eclodibilidade de ovos (TEO), que se baseia na incubação dos ovos do parasito em uma série de concentrações do anti-helmíntico. É utilizado principalmente para 0 albendazol comercial, para avaliação de seus efeitos sobre os ovos dos nematoides (FORTES; MOLENTO, 2013).

0 TEO tem sido utilizado com várias modificações por alguns pesquisadores para a detecção de resistência ao grupo dos BZs, cuja ação é impedir a embriogênese e a eclosão das larvas de nematoides que tiveram contato com concentrações crescentes do fármaco (FORTES; MOLENTO, 2013). No entanto, há poucos relatos de testes in vitro validados até 0 momento, que necessitam ser mais estudados $\mathrm{e}$ padronizados entre os laboratórios brasileiros.

0 objetivo deste trabalho foi padronizar, adaptar e detalhar 0 teste de eclodibilidade de ovos (TEO) para o diagnóstico da resistência de nematoides gastrintestinais de ovinos ao albendazol.

\section{MATERIAL E MÉTODOS}

Estudo aprovado pelo protocolo 013/2014 da Comissão de Ética no Uso de Animais da Universidade Federal do Espírito Santo.

Foram coletadas amostras de fezes frescas de um ovino com histórico de tratamentos sucessivos com o princípio ativo albendazol. A coleta foi realizada diretamente da ampola retal utilizando sacos plásticos e encaminhados ao Laboratório de Parasitologia do Hospital Veterinário da Universidade Federal do Espírito Santo (HOVET-UFES), em caixa térmica para posterior análise laboratorial, utilizando a técnica McMaster (OPG) (GORDON; WHITLOCK, 1939) com determinação do grau de parasitismo e também foi realizada a coprocultura pela técnica de Roberts e 0'Sullivan (1950), para identificação dos gêneros de nematoides presentes.

Para a realização do teste in vitro - teste de eclodibilidade de ovos (TEO) - foram utilizadas amostras de fezes frescas, imediatamente após a coleta. Foram realizados três ensaios do TEO em dois momentos diferentes (24 e 48h), utilizando diferentes amostras fecais do mesmo animal doador para cada ensaio.

Com 0 intuito de padronizar a técnica no laboratório, a recuperação dos ovos inicialmente seguiu a metodologia do Manual Técnico da Empresa Brasileira de Pesquisa Agropecuária (EMBRAPA) (CHAGAS, NICIURA; MOLENTO, 2011). As fezes foram coletadas diretamente da ampola retal, maceradas e acrescentadas de água morna $\left( \pm 40^{\circ} \mathrm{C}\right)$, posteriormente foram filtradas em quatro peneiras granulométricas com reticulações de $980 \mu \mathrm{m}, 149 \mu \mathrm{m}, 62 \mu \mathrm{m}$ e $25 \mu \mathrm{m}$. Os ovos retidos na última malha de diâmetro de 25 $\mu \mathrm{m}$, foram lavados com água destilada com auxílio de pisseta, passando 0 conteúdo ali retido para tubos, tipo Falcon de $50 \mathrm{~mL}$, que foram centrifugados a $3.000 \mathrm{rpm}$ por 05 minutos em centrífuga refrigerada a $40^{\circ} \mathrm{C}$ (Nova Técnica ${ }^{\circledR}$ NT 825).

Após centrifugação, descartou-se 0 sobrenadante, completou-se com solução de sacarose saturada para promover a suspensão dos ovos, 
centrifugou-se por mais 05 minutos a $3.000 \mathrm{rpm}$, despejou-se 0 sobrenadante na peneira de $25 \mu \mathrm{m}$ novamente e lavaram-se os ovos ali retidos com água destilada, posteriormente despejando num cálice de decantação por 30 minutos à temperatura ambiente.

Entretanto, esse protocolo foi repetido em sete ensaios, e em nenhum deles os ovos foram recuperados com sucesso. Diante deste fato, como alternativa optou-se seguir a fase de recuperação dos ovos de nematoides gastrintestinais de acordo com Coles et al. (1992), modificado por Bizimenyera et al. (2006).

Portanto, as amostras fecais foram novamente coletadas, diluídas em água morna, evitando-se estresse térmico, lavadas em quatro peneiras com diferentes reticulações $(980 \mu \mathrm{m}, 149 \mu \mathrm{m}, 62 \mu \mathrm{m}$ e $25 \mu \mathrm{m})$ e recuperadas da última malha de $25 \mu \mathrm{m}$. 0 conteúdo foi transferido para tubo tipo Falcon de 50 $\mathrm{mL}$ e centrifugado com água destilada, descartou-se o sobrenadante e completou-se com concentrações diferentes de sacarose $(20 \%, 30 \%, 60 \%)$, formando gradientes de concentrações em diferentes fases, que posteriormente foram centrifugados, coletados os ovos com auxílio de pipeta automática (LabMate ${ }^{\circledR}$ $100-1000 \mu \mathrm{L})$, transferidos para um novo tubo tipo Falcon de $15 \mathrm{~mL}$ e acrescentado água destilada para retirar 0 excesso da sacarose e promover a limpeza dos mesmos.

Após 0 processo de centrifugação, concentraram-se os ovos em apenas um nível, que foi no halo formado entre a solução de fezes, água e ovos com a solução a $20 \%$ de sacarose. Com essa modificação foi possível visualizar macroscopicamente uma massa branca de ovos, que foram pipetados e repassados para tubos Falcon de $15 \mathrm{~mL}$. Após a recuperação dos ovos, foram adicionados a cada poço, $500 \mu \mathrm{L}$ de água contendo em média 100 ovos, estimados em três alíquotas de $10 \mu \mathrm{L}$. Do momento da coleta das fezes até 0 término da preparação das placas, não foi ultrapassado mais que 03 horas de manipulação, evitando, assim, a inviabilização dos ovos.

Em seguida, nos mesmos poços que foram distribuídos os ovos, adicionaram-se $500 \mu \mathrm{L}$ da solução tratamento. 0 anti-helmíntico sulfóxido de albendazol, solução injetável $(1 \mathrm{~mL} / 40 \mathrm{~kg})$, produto Voss Rico ${ }^{\circledR}$ (Ouro Fino) foi diluído em DMSO a 0,75\% e água destilada e posteriormente fracionado em nove concentrações seriadas $(600 ; 300 ; 150 ; 112,5$; $75 ; 37,5 ; 18,75 ; 9,37$ e $4,68 \mu \mathrm{g} / \mathrm{mL}$ ) de acordo com 0 recomendado pelo Manual Prático da EMBRAPA (CHAGAS; NICIURA; MOLENTO, 2011).

Para o controle positivo, a dose máxima do fármaco utilizada foi de $25.000 \mu \mathrm{m} / \mathrm{mL}$ na qual nenhum ovo ficaria viável e para os controles negativos, DMSO $0,75 \%$ e água destilada foram utilizados na mesma quantidade.

Para a execução do teste foi utilizada a metodologia preconizada pelo Manual Prático da EMBRAPA e os ensaios foram realizados em triplicata para cada concentração do fármaco, controle negativo e controle positivo, utilizando-se placa de cultivo celular (24 poços).

Seguiu-se incubação das placas em estufa com demanda bioquímica de oxigênio (D.B.0), mantidos à temperatura de $28^{\circ} \mathrm{C}$. Dos seis ensaios realizados, a leitura de três deles foi realizada após 24 horas de incubação e de outros três ensaios com 48 horas de incubação. A leitura foi realizada em microscópio invertido (Zeiss ${ }^{\circledR}$ ), modelo Axiovert $40 \mathrm{CFL}$, em aumento de 10x. As larvas eclodidas e os ovos foram analisados e quantificados.

Os dados foram compilados em planilhas do Microsoft Excel e analisados por estatística descritiva mediante ao cálculo de eficácia do teste in vitro, segundo Coles et al. (1992). A taxa de eclodibilidade no teste in vitro foi expressa em percentual pela seguinte fórmula: taxa de eclodibilidade $(\%)=$ [número de larvas / (número de ovos + larvas) x 100]. Foi utilizado o teste "t" de Student para comparação entre as médias nos dois momentos de observação (24 e 48h), usando nível de significância de 5\% no programa Biostat 5.0. 


\section{RESULTADOS E DISCUSSÃO}

0 resultado de OPG referente ao exame de triagem (anterior ao protocolo experimental) foi positivo para ovos do tipo Strongyloidea e também para ovos do gênero Strongyloides. De acordo com Ueno e Gonçalves (1998), infecções mistas em ovinos são consideradas moderadas quando o número de OPG é superior a 1.000, 0 que já pode ser sugestivo de tratamento, a depender de outros fatores, como estado nutricional e clínico do animal.

$\mathrm{Na}$ leitura da coprocultura foi observado infecção mista com predominância dos gêneros Haemonchus sp. e Trichostrongylus sp., com percentual de $49 \%$ e $51 \%$, respectivamente. Esses resultados foram semelhantes aos resultados obtidos por Gugel et al. (2012) em Santa Catarina, por Sczesny-Moraes et al. (2010) no Mato Grosso do Sul e por Silva et al. (2010) no Mato Grosso, este último com relato de que em $100 \%$ das coproculturas, as infecções por esses dois gêneros prevaleceram em cerca de 50\%.

Para o diagnóstico preciso da resistência parasitária nesse animal buscou-se a realização do teste in vitro, no qual foi observado que ao inserir três concentrações distintas de sacarose $(20 \%, 30 \%$, $60 \%$ ), e não apenas uma concentração como no teste preconizado pela EMBRAPA, o diferencial foi a promoção dos diferentes gradientes formados, que por diferença de densidade, atuaram na flutuação dos ovos em um único ponto. Esta fase fez toda diferença na recuperação e viabilidade dos ovos, já que quando realizado seguindo as recomendações da EMBRAPA os ovos não foram passíveis de recuperação, pois se perdiam durante os processos de flutuação e decantação.

Apesar de 0 Manual Prático da EMBRAPA (CHAGAS; NICIURA; MOLENTO, 2011) indicar o uso de peneiras com reticulações de $1 \mathrm{~mm}, 105 \mu \mathrm{m}, 53 \mu \mathrm{m}$ e $25 \mu \mathrm{m}$, neste estudo utilizando outras três peneiras com reticulações distintas das recomendadas (980 $\mu \mathrm{m}, 149 \mu \mathrm{m}$ e $62 \mu \mathrm{m})$, não foram observados prejuízos na recuperação dos ovos, é importante frisar que a utilização da última peneira que possui abertura de 25 $\mu \mathrm{m}$, onde os ovos ficam retidos é fundamental.

Foi avaliado o percentual médio da eclosão das larvas nos três ensaios e indica-se a leitura dos ensaios após $24 \mathrm{~h}$ de incubação dos ovos, pois a média dos controles negativos (água destilada e DMSO 0,75\%) assim como das concentrações 4,68, 9,37, 18,75 $\mu \mathrm{g} /$ $\mathrm{mL}$ foram mais baixas após $48 \mathrm{~h}$ de incubação, sendo recuperadas poucas larvas independentemente do tratamento (Tabela 1). Vale ressaltar que os resultados foram significativamente diferentes no primeiro e terceiro ensaios $(p<0,01)$.

Tabela 1. Percentual médio de eclosão de larvas de nematoides gastrintestinais dos ensaios realizados com $24 \mathrm{~h}$ e 48h após a incubação dos ovos

\begin{tabular}{lcc}
\hline Tratamento & 24h & 48h \\
\hline Controle - (Água destilada) & 71,55 & 44,19 \\
Controle - (DMSO 0,75\%) & 82,76 & 53,00 \\
$4,68 \mu \mathrm{g} / \mathrm{mL}$ & 71,02 & 39,08 \\
$9,37 \mu \mathrm{g} / \mathrm{mL}$ & 80,29 & 44,10 \\
$18,75 \mu \mathrm{g} / \mathrm{mL}$ & 54,90 & 31,29 \\
$37,5 \mu \mathrm{g} / \mathrm{mL}$ & 32,58 & 1,55 \\
$75 \mu \mathrm{g} / \mathrm{mL}$ & 1,02 & 0,21 \\
$112,5 \mu \mathrm{g} / \mathrm{mL}$ & 0,17 & 0,00 \\
$150 \mu \mathrm{g} / \mathrm{mL}$ & 0,00 & 0,00 \\
$300 \mu \mathrm{g} / \mathrm{mL}$ & 0,00 & 0,00 \\
$600 \mu \mathrm{g} / \mathrm{mL}$ & 0,00 & 0,00 \\
Controle + (albendazol 25mg/mL) & 0,00 & 0,00 \\
\hline
\end{tabular}

Fonte: (MARTINS; MARTINS, 2016).

Segundo Samson-Himmelstjerna et al. (2009), ocasionalmente larvas não eclodem em poços de controle. As razões não são certas, por isso recomendase aceitar apenas os testes em que a taxa de eclosão em ambos os poços de controle seja de pelo menos $70 \%$. No presente estudo isso não ocorreu com 48h.

Quanto à avaliação da resistência dos nematoides ao albendazol nesse estudo, não foi possível determinar devido à falta de literatura sobre a dose de eficácia in vitro, também denominada de dose discriminante. Nos estudos in vitro, segundo Coles et al. 
(2006), a dose discriminante é a que impede a eclosão de $99 \%$ das larvas. Neste estudo, considerando a avaliação após 24h de incubação, a dose discriminante foi $112,5 \mu \mathrm{g} / \mathrm{mL}$, porém nenhum estudo na literatura consultada apresenta ou discute esse valor.

Uma provável sugestão paraestudos posteriores seria consultar em literatura qual a concentração em nível plasmático do albendazol após metabolização no fígado depois do tratamento oral do animal a ser testado, e a partir desse valor, seriar concentrações inferiores e superiores a esta para serem testados no TEO. Muitos trabalhos relatam doses discriminantes apenas para 0 tiabendazol (ALBONICO et al., 2005; SAMSON-HIMMELSTJERNA et al., 2009), porém para 0 albendazol as concentrações são apenas descritas no Manual da Embrapa, mas sem determinação da dose discriminante.

Alguns fatores em investigação, e que podem influenciar os resultados obtidos com o TEO, incluem: o método de dissolução da solução tratamento (DMSO ou água); diferentes fontes de água utilizada (destilada, deionizada ou água de torneira) e grau de limpeza dos ovos (presença de detritos) (COLES et al., 2006).

A maioria dos autores sugere correlacionar 0 TRCOF com 0 TEO e futuramente utilizar apenas 0 TEO para detecção da resistência. Entretanto, diante do exposto, é necessária a padronização do teste nos diferentes laboratórios brasileiros.

\section{CONCLUSÕES}

Neste estudo não foi possível diagnosticar a resistência anti-helmíntica dos nematoides gastrintestinais ao albendazol no TEO, devido à falta de informação sobre a dose discriminante. Porém, foi possivel a padronização, a adaptação e 0 detalhamento do teste. Para esses testes in vitro, muitos ensaios devem ser reproduzidos a fim de se definir um procedimento operacional padrão com as possiveis interpretações quanto às variáveis que influenciam negativamente a execução do teste.

\section{REFERÊNCIAS}

ALBONICO, M. et al. Development of the egg hatch assay for detection of anthelminthic resistance in human hookworms. International Journal for Parasitology, v. 35, n. 7, p. 803-811, 2005.

AMARANTE, A. F. T. et al. Resistance of Santa Inês, Suffolk and lle de France sheep to naturally acquired gastrointestinal nematode infections. Veterinary Parasitololy, v. 120, n. 2, p. 91-106, 2004.

BIZIMENYERA, E. S. et al. E. In vitro activity of Peltophorum africanum Sond. (Fabaceae) extracts on the egg hatching and larval development of the parasitic nematode Trichostrongylus colubriformis. Veterinary Parasitology, v. 142, n. 3, p. 336-343, 2006.

BRASIL, Portaria SDA nº 48, de 12 de maio de 1997. Aprova como anexo o Regulamento Técnico a ser observado na produção, no controle e no emprego de antiparasitários de uso veterinário. Legislação relacionada aos produtos de uso veterinário. Brasília, 2012.

CHAGAS, A. C. S.; NICIURA, S. C. M.; MOLENTO, M. B. Manual Prático: metodologias de diagnóstico da resistência e de detecção de substâncias ativas em parasitas de ruminantes. Embrapa Informação Tecnológica, Brasília, DF, 2011. 153 p.

COLES, C. G. et al. The detection of anthelmintc resistance in nematodes of veterinary importance. Veterinary Parasitology, v. 136, n. 3, p. 167-185, 2006.

COLES, G. C. et al. World Association for the Advancement of Veterinary Parasitology (WAAVP) methods for the detection of anthelmintic resistance in nematodes of veterinary importance. Veterinary Parasitology, v. 44, n. 3, p. 35-44, 1992.

FORTES F. S.; MOLENTO M. B. Resistência antihelmíntica em nematóides gastrintestinais de pequenos ruminantes: avanços e limitações para seu diagnóstico. Pesquisa Veterinária Brasileira, v. 33, n. 12, p. 1391-1402, 2013. 
GORDON, H. M. C.; WHITLOCK, H. V. A new technique

Recebido em: 30/09/2019 for counting nematode eggs in sheep faeces. Journal of Commo nwealth Science and Industry Research Organization, v. 12, n. 1, p. 50-52, 1939.

GUGEL, M. et al. Prevalência de endoparasitas em ovinos no oeste de Santa Catarina: resultados preliminares. Synergismus Scyentifica, v.7, n.1, p.13, 2012.

KAPLAN, R. M.; VIDYASHANKAR, A. N. An inconvenient truth: Global worming and anthelmintic resistance. Veterinary Parasitology, v. 186, n. 12, p. 70-78, 2012.

ROBERTS, F. H. S.; O'SULLIVAN, J. P. Methods for egg count sand larval cultures for strongyles infesting the gastrointestinal tract of cattle. Autralian Journal of Agricutural Research, v. 1, n. 1, p. 99-102, 1950.

SAMSON-HIMMELSTJERNA, G. et al. Standardization of the egg hatch test for the detection of benzimidazole resistance in parasitic nematodes. Parasitology Research, v. 105, n. 2, p. 825-834, 2009.

SCZESNY-MORAES, E. A. et al. Resistência antihelmíntica de nematóides gastrintestinais em ovinos, Mato Grosso do Sul. Pesquisa Veterinária Brasileira, v. 30, n. 3, p. 229-236, 2010.

SILVA, M. R. L. et al. Parasitas gastrintestinais de ovinos criados na região de Rondonópolis-MT.

Revista Biodiversidade, v. 9, n. 1, p. 67-73, 2010.

UENO, H.; GONÇALVES, P. C. Manual para

Diagnóstico das Helmintoses de Ruminantes. 4. ed., Tokyo: Japan International Cooperation Agency, 1998. 55p.

W00D, I. B. et al. World Association for the Advancement of Veterinary Parasitology (W.A.A.V.P.) second edition of guidelines for evaluating the efficacy of anthelmintics in ruminants (bovine, ovine, caprine). Veterinary Parasitology, v. 58, n. 3, p. 181-213, 1995. 